\title{
AVRIL 1975
}

57• ANNÉE - N॰ 676

\section{revue internationale de la croix-rouge}

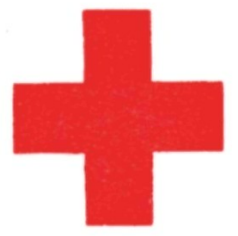

\section{GENEेVE}

COMITÉ INTERNATIONAL DE LA CROIX-ROUGE FONDÉ EN 1863 


\title{
COMITÉ INTERNATIONAL DE LA CROIX-ROUGE
}

MM. ERIC MARTIN, docteur en médecine, professeur honoraire de l'Université, Genève, président (membre depuis 1973)

JEAN PICTET, docteur en droit, président de la Commission juridique, professeur associe à l'Université, Genève, vice-président (1967)

HARALD HUBER, docteur en droit, juge fédéral, vice-président (1969)

HANS BACHMANN, docteur en droit, directeur des finances de la ville, Winterthour (1958)

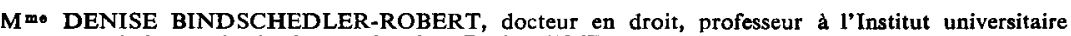
de hautes études internationales, Genève (1967)

MM. MARCel A. NAVILLE, licencié ès lettres, président đu CICR de 1969 à 1973 (1967)

JACQUES F. DE ROUGEMONT, docteur en médecine (1967)

ROGER GALLOPIN, docteur en droit, ancien directeur général du CICR (1967)

WALDEMAR JUCKER, docteur en droit, secrétaire de l'Union syndicale suisse (1967)

VICTOR H. UMBRICHT, docteur en droit, administrateur (1970)

PIERRE MICHELI, licencié en droit, ancien ambassadeur (1971)

GILBERT ETIENNE, professeur à l'Institut universitaire de hautes études internationales et à l'Institut d'études du développement, Genève (1973)

ULRICH MIDDENDORP, docteur en médecine, chef de la clinique chirurgicale de l'Hôpital cantonal, Winterthour (1973)

$M^{\text {me }}$ MARION BOVÉE-ROTHENBACH, diplômée M.S.W. de l'Université de Michigan, małtreassistant à l'Ecole des sciences sociales et politiques de l'Université, Lausanne (1973)

MM. HANS PETER TSCHUDI, docteur en droit, ancien conseiller fédéral (1973)

HENRY HUGUENIN, directeur de banque (1974)

GOTTFRIED DE SMIT, administrateur (1974)

JAKOB BURCKHARDT, docteur en droit, ministre plénipotentiaire, président du Conseil des Ecoles polytechniques fédérales (1975)

THOMAS FLEINER, docteur en droit, professeur à l'Université de Fribourg (1975)

ALEXANDRE HAY, avocat, directeur général de la Banque nationale suisse (1975)

Membres honoraires: M. JACQUES CHENEVIERE, vice-président d'honneur; $\mathrm{M}^{11 \mathrm{e}}$ LUCIE ODIER, vice-présidente d'honneur; MM. GUILLAUME BORDIER, PAUL CARRY, $M^{\text {* }}$ MARGUERITE GAUTIER-VAN BERCHEM, MM. SAMUEL A. GONARD, ADOLPHE GRAEDEL, EDOUARD DE HALLER, RODOLFO OLGIATI, MAX PETITPIERRE, PAUL RUEGGER, DIETRICH SCHINDLER, FREDERIC SIORDET, ALFREDO VANNOTTI.

\section{CONSEIL EXÉCUTIF}

\author{
M. ROGER GALLOPIN, président \\ M. VICTOR H. UMBRICHT, vice-président \\ $M^{\text {me }}$ DENISE BINDSCHEDLER-ROBERT \\ M. GILBERT ETIENNE \\ D' ULRICH MIDDENDORP \\ M. JEAN PICTET \\ M. GOTTFRIED DE SMIT \\ M. PIERRE MICHELI, membre suppleant
}




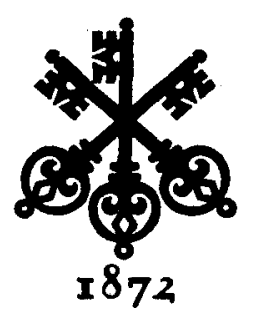

PRÉSENTE SUR LES CINQ CONTINENTS,

LA GRANDE BANQUE AUX TROIS CLEFS

EST À VOTRE DISPOSITION POUR EFFECTUER

TOUTES VOS OPÉRATIONS FINANCIËRES

\section{SOCIÉTÉ DE BANQUE SUISSE}

SCHWEIZERISCHER BANKVEREIN - SOCIETA DI BANCA SVIZZERA

SWISS BANK CORPORATION

SIËGE DE GENEVE

2, RUE DE LA CONFÉDÉRATION

TÉL. 201111

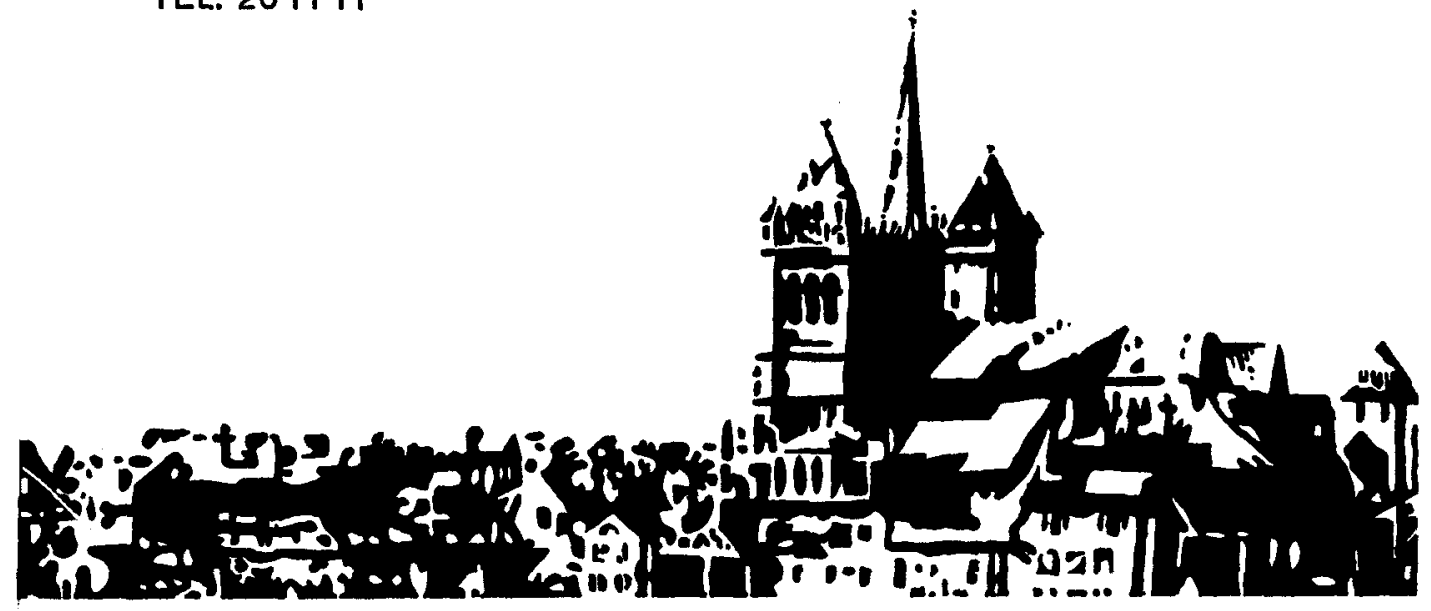




\section{SOCIETE FIDULIAIRE ROMANDE OFOR S.A.}

Place Saint-Gervais 1, Genève - Tél. 317050

Expertises, révisions et organisations comptables

Domiciliation et administration de sociétés

Assainissements et liquidations

Interventions et conseils en matière fiscale

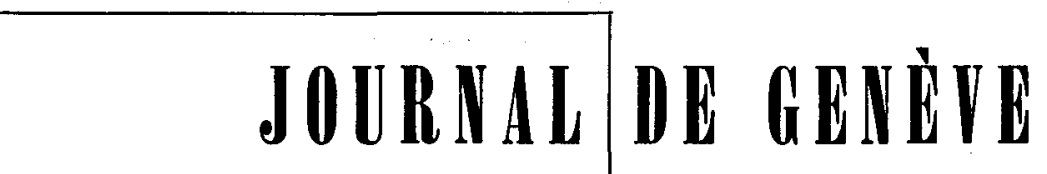

deux imprimeries

deux adresses

rue François-Dussaud 20

1211 Genève 8 - Téléphone 431940

rue Général-Dufour 5-7

1211 Genève 11 - Téléphone 250350

TYPO - OFFSET - ROTATIVE 


\section{REVUE INTERNATIONALE DE LA CROIX-ROUGE}

AVRIL 1975 - № 676

COMITÉ INTERNATIONAL

DE LA CROIX-ROUGE

\section{DANS LE MONDE DE LA CROIX-ROUGE}

\section{FAITS ET DOCUMENTS}

Conférence diplomatique sur la réaffirmation et le développement du droit international humanitaire applicable dans les conflits armés . . . . 197

J. Moreillon : Le Comité international de la CroixRouge et la protection des détenus politiques . 201

L'action du Comité international à Chypre . . . 214 Activités extérieures:

Afrique - Amérique latine - Asie - Europe Moyen-Orient . . . . . . . . . . . 218 A Genève:

Les hôtes du CICR . . . . . . . . . . . . . 224

Décès d'un ancien rédacteur en chef de la Revue 225

Un appel de la Croix-Rouge . . . . . . . . . 226

Diffusion des Conventions de Genève:

Espagne-Pologne-République démocratique allemande - Thaïlande . . . . . . . . 227

«Croix-Rouge: votre sauvegarde dans l'urgence » 230

Turquie . . . . . . . . . . . . . . 232

Symposium sur le développement de la Croix-

Rouge en Afrique . . . . . . . . . . . . . . . 234

250000 personnes rapatriées dans le sous-continent asiatique . . . . . . . . . . 235

Les inquiétudes du médecin et les soucis du biologiste . . . . . . . . . . . . . . . . 237

Les tâches des auxiliaires médicaux . . . . . . 241 


\section{INTERNATIONAL REVIEW \\ OF THE RED CROSS}

\section{EXTRAITS \\ de la reVue}

EN LANGUE ESPAGNOLE

EN LANGUE ALLEMANDE

REVUE INTERNATIONALE DE LA CROIX-ROUGE
Une édition en langue anglaise paraitt chaque mois. Ello est en principe identique a l'édition française, et peut être obtenue aux mêmes conditions.

Jean Pictet: El péndulo de la historia - VII Reunión Regional de las Sociedades Árabes de la Media Luna Roja y de la Cruz Roja.

Jean Pictet: Das Pendel der Geschichte - VII. Regionalkonferenz der arabischen Rotkreuz- und Rothalbmondgesellschaften.

Elle est publice chaque mois par le Comité international de la Croix-Rouge.

17, avenue de la Paix, 1211 Genève (Suisse) - Compte de chèques postaux $12-1767$.

Abonnement un an: Fr. 30,--; le numéro: Fr. 3,-.

RÉDACTION : J.-G. LOSSIER

Seuls les textes signés par le Comité international de la Croix-Rouge engagent la responsabilité de celui-ci. 